\title{
IMMUNOCYTOCHEMICAL INVESTIGATION OF SEROTONERGIC INPUTS TO VASOACTIVE INTESTINAL PEPTIDE (VIP)-CONTAINING NEURONS IN THE RAT SUPRACHIASMATIC NUCLEUS
}

\section{Fumio KaWAKAMI}

Department of Psychiatry, Kyoto Prefectural University of Medicine, Kawaramachi-Hirokoji, Kamikyoku, Kyoto 602, Japan

\begin{abstract}
The influence of serotonergic inputs on vasoactive intestinal peptide (VIP)-containing neurons in the rat suprachiasmatic nucleus (SCN) was examined using peroxidase-antiperoxidase immunocytochemistry. Serotonergic inputs were blocked by 1) chemical destruction of the ascending serotonergic pathway by 5,6-dihydroxytryptamine injected into the medial forebrain bundle, 2) intraperitoneal injections of reserpine for successive 7 days, and 3) intraperitoneal injections of methysergide for successive 7 days. These treatments caused a marked depletion of VIP-like immunoreactivity in neuron perikarya in the ventral portion of SCN, with a concomitant decrease in the number of serotonin-immunoreactive fibers and terminals. The findings suggest the possibility that VIP-containing neurons may play a role in regulating the circadian rhythm in SCN under a strong influence of serotonergic innervation.
\end{abstract}

The suprachiasmatic nucleus (SCN) plays an important role as the center of circadian rhythm in mammals $(20,21,30)$. The ascending innervation of the serotonergic neuron system is one of the major afferent projections to $\operatorname{SCN}(8,28)$. Recent progress in radioimmunoassay and immunocytochemistry has demonstrated several kinds of peptide-containing neurons with characteristic distributions in $\operatorname{SCN}(17,35)$. Vasoactive intestinal peptide (VIP) is one of the representative peptides in $\operatorname{SCN}(17,27,31)$, and suggestions have been made that VIP may act as a neurotransmitter $(3,7,9,18,32)$. The distribution of VIP-containing neurons is similar to that of the serotonergic terminals in the nucleus. In addition, serotonergic terminals were found to form synaptic contacts with VIP-like immunoreactive perikarya using a combination of autoradiography and immunocytochemistry at the electron microscopic level (15).

Catecholaminergic inputs have previously been reported to affect the peptide-containing neurons in the paraventricular nucleus of the hypothalamus $(14,19)$ and the central nucleus of the amygdala (13). The purpose of this study is to ascertain the influence of ascending serotonergic inputs on VIP-containing neurons in SCN by analyzing alterations in VIP-like immunoreactivity caused by blocking serotonergic inputs to this nucleus.

\section{MATERIALS AND METHODS}

Seventy-five male albino Wistar rats were divided into the following four groups: 1) untreated controls, 2) rats that received chemical transection of the ascending serotonergic pathway, 3) rats that received intraperitoneal injections of reserpine, and 4) rats that 
received intraperitoneal injections of methysergide.

\section{Chemical Transection}

To destroy the ascending serotonergic pathway, 5,6-dihydroxytryptamine (5,6-DHT), a false transmitter of serotonin $(4,6,25)$, was slowly infused bilaterally into the medial forebrain bundle (MFB) at the caudal hypothalamic level using a stereotaxic instrument. Infusion of 5,6-DHT into the unilateral MFB decreased insufficiently the number of serotonin-immunoreactive terminals in the bilateral SCN. The dose of 5,6-DHT was $25 \mu \mathrm{g}$, dissolved in $10 \mu$ l Ringer solution containing $0.2 \mathrm{mg} / \mathrm{ml}$ ascorbic acid (6). The control rats recieved $10 \mu \mathrm{l}$ Ringer solution containing $0.2 \mathrm{mg} / \mathrm{ml}$ ascorbic acid. The coordinates were determined accòrding to König and Klippel (16): A, 3.4; L, \pm 1.5 ; and V, -7.6 from the surface of the brain. The operation was performed under pentobarbital anesthesia $(60 \mathrm{mg} / \mathrm{kg}$ body wt.; intraperitoneal injection). Animals were killed 7 days after the operation.

\section{Drug Administration}

Reserpine $(5 \mathrm{mg} / \mathrm{kg}$ ) or methysergide $(2 \mathrm{mg} /$ $\mathrm{kg}$ ) was injected intraperitoneally once daily for 7 days. The control rats daily received one intraperitoneal injection of saline for 7 days. All injections were given at 10 a.m. Animals were killed $24 \mathrm{~h}$ after the last injection.

\section{Immunocytochemistry}

All animals were perfused via the left cardiac ventricle with ice-cold $0.1 \mathrm{M}$ phosphate-buffered saline (PBS, pH 7.4), followed by a fixative consisting of $4 \%$ paraformaldehyde, $0.35 \%$ glutaraldehyde and $0.2 \%$ picric acid in $0.1 \mathrm{M}$ phosphate buffer ( $\mathrm{pH}$ 7.4). The brains were immediately removed and immersed in the same fixative without glutaraldehyde for $48 \mathrm{~h}$ at $4^{\circ} \mathrm{C}$.

Frontal cryostat sections, $20 \mu \mathrm{m}$ thick, were made serially and divided into two groups (vide infra). All sections were immersed in PBS containing $0.3 \%$ Triton $\mathrm{X}-100$ for 4 days at $4^{\circ} \mathrm{C}$, and then in bovine serum albumin (dilution $1: 100$ ) for $60 \mathrm{~min}$. Then, the first group of sections was incubated with anti-VIP antiserum (R502; reference 36; dilution $1: 5,000)$ for 7 days at $4^{\circ} \mathrm{C}$, with goat anti-rab- bit IgG (Miles-Yeda, dilution 1:200) for $120 \mathrm{~min}$, and with the rabbit peroxidase-antiperoxidase (PAP) complex solution (Dakopatts a/s, dilution $1: 200$ ) for $90 \mathrm{~min}$ at room temperature. The second group of sections was incubated with anti-serotonin antiserum (Sera-Laboratories, YC/HLK; reference 5; dilution $1: 100$ ) for 7 days at $4^{\circ} \mathrm{C}$, with goat anti-rat IgG (Immuno Nuclear Corp.; dilution $1: 100)$ for $120 \mathrm{~min}$, and finally with the rat PAP complex solution (Immuno Nuclear Corp.; dilution $1: 100$ ) for $90 \mathrm{~min}$ at room temperature. For a detailed comparison of the distribution between serotonergic terminals and VIP-containing neurons, thin serial sections, $4 \mu \mathrm{m}$ thick, were made from some tissue blocks of the untreated rat brains including the hypothalamus. These sections were incubated alternately with anti-serotonin antiserum or anti-VIP antiserum for $12 \mathrm{~h}$ at room temperature, and processed with anti-rabbit IgG or anti-rat IgG, and finally with the PAP complex solution. All sera were diluted with 0.1 M PBS containing $0.3 \%$ Triton X-100, and between each step the sections were washed with the same solution. Finally, all sections were allowed to react with $0.02 \% 3,3^{\prime}$-diaminobenzidine $4 \mathrm{HCl}$ in $50 \mathrm{mM}$ Tris buffer $(\mathrm{pH} 7.5)$ containing $\mathrm{H}_{2} \mathrm{O}_{2}$. The sections were mounted on glass slides and examined under a light microscope.

The specificity of anti-VIP antiserum was confirmed by preabsorption with synthetic VIP $(1-100 \mu \mathrm{g} / \mathrm{ml})$, and the specificity of antiserotonin antiserum by preabsorption with serotonin $(10 \mu \mathrm{g} / \mathrm{ml})$. No positive immunoreactivity was detected in any section after the absorption test. The specificity and cross-reactivity of these antisera have been described in detail elsewhere $(5,36)$.

\section{RESULTS}

\section{Serotonin-Immunoreactive Terminals and VIP-like Immunoreactive Perikarya in SCN of the Control Rat}

The rostral portion of SCN contained many serotonin-immunoreactive terminals mainly in its ventral portion. The proportion of serotonin-immunoreactive terminals was increased in the central SCN (Fig. 1a). The highest population of serotonin-immunoreactive terminals was observed in the central $\mathrm{SCN}$, particularly in its ventral half. The number of serotonin-immunoreactive terminals was decreased in the dorsal portion of SCN 

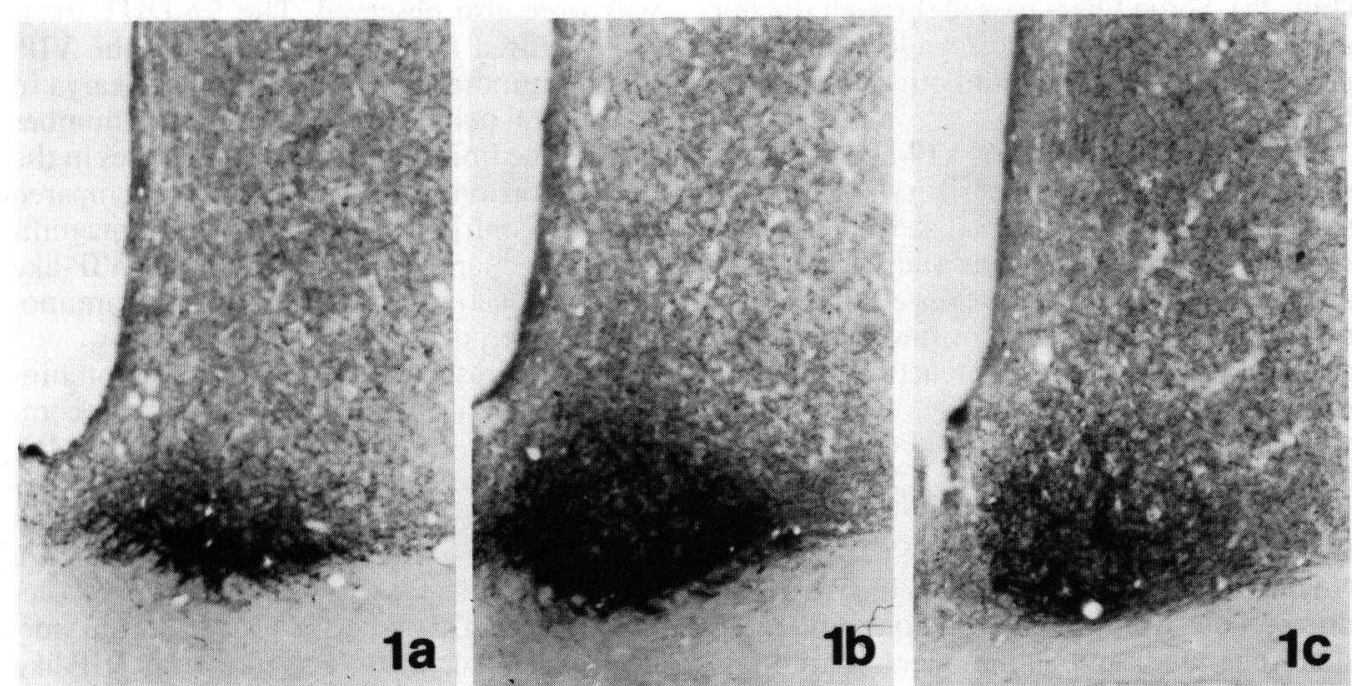

Fig. 1 Serotonin-immunoreactive terminals in the rostral (a), central (b) and caudal (c) SCN of untreated rats. Many serotonin-immunoreactive terminals were observed in the ventral portion. $\times 85$
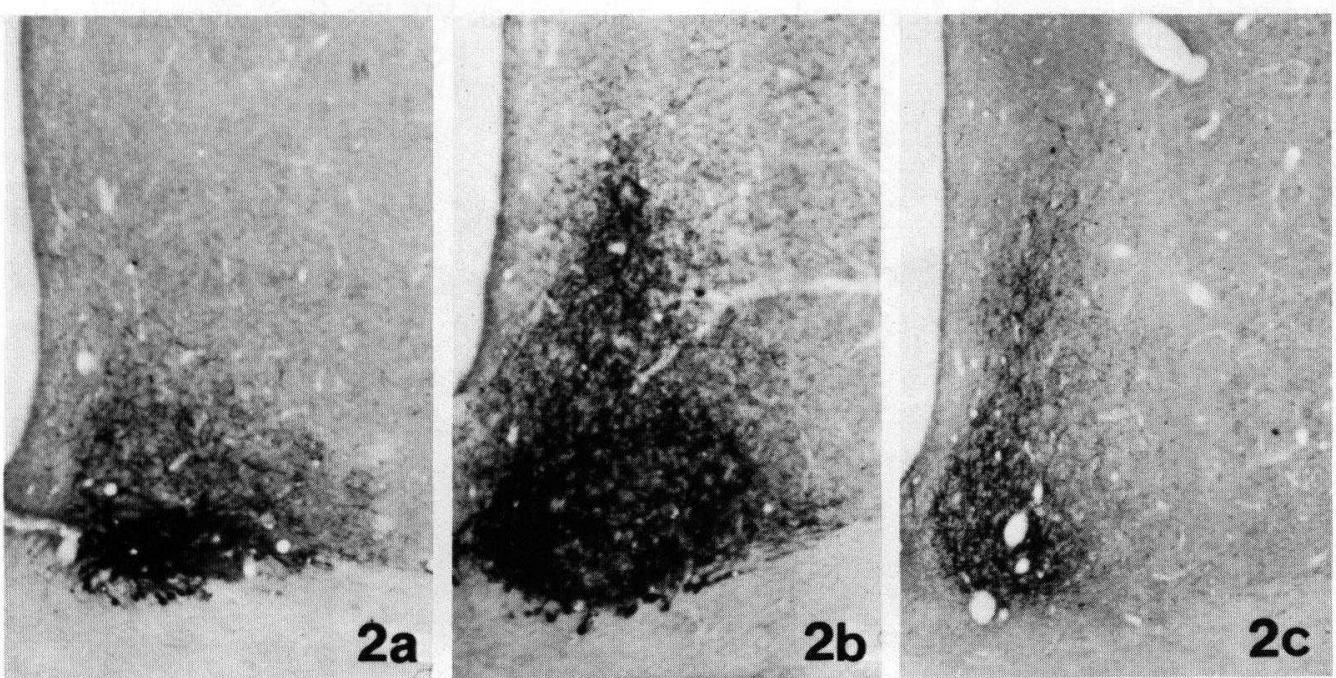

Fig. 2 VIP-like immunoreactive neuron perikarya, fibers and terminals in the rostral (a), central (b) and caudal (c) SCN of the untreated rat. Many VIP-like immunoreactive neuron perikarya were observed in the ventral portion. VIP-like immunoreactive fibers and terminals were seen in the dorsal portion; some fibers passed SCN and extended toward the other hypothalamic areas (c). a and b, $\times 85 . c, \times 60$

(Fig. 1b). Serotonin-immunoreactive terminals were fewer in the caudal SCN than in the central SCN (Fig. 1c). Serotonin-immunoreactive terminals in the ventral portion of the caudal SCN were not as densely stained as those in the central SCN.

A small number of VIP-like immunoreactive perikarya were distributed in the ventral portion of the rostral SCN. However, VIP-like immunoreactive fibers and terminals were relatively abundant in the ventral and dorsal portions of SCN (Fig. 2a). The central SCN contained most of the VIP-like immunoreactive perikarya, particularly in its ventral portion. In the dorsal SCN, VIP-like immunoreactive fibers and terminals were abundant 
(Fig. 2b). Some fibers passed through the dorsal portion (Fig. 2c) and extended toward the paraventricular nucleus and other parts of the hypothalamus.

In thin sections $(4 \mu \mathrm{m})$, VIP-like immunoreactivity was located in perikarya of a smaller size and of oval or spherical shape. Comparison with adjacent sections stained with the anti-serotonin antiserum revealed that serotonin-immunoreactive varicosities were located around the VIP-immunoreactive neuronal somata (Fig. 3, a and b).

\section{Alterations in Serotonin and VIP-like Immunoreactivity after the Treatments}

No differences in serotonin or VIP-like immunoreactivity were observed among untreated, sham-operated, and saline-injected animals.

After the 5,6-DHT treatment, the number of serotonin-immunoreactive terminals in SCN was markedly decreased (Fig. 4b) compared with the control (Fig. 4a). Some swollen serotonin-immunoreactive fibers and termi- nals were also observed. The 5,6-DHT treatment caused a marked decrease in the VIPlike immunoreactivity of neuron perikarya in the ventral portion of $\mathrm{SCN}$ and in the number of VIP-like immunoreactive varicosities in the dorsal portion of SCN (Fig. 5b), compared with the control (Fig. 5a). At a higher magnification, a marked depletion of the VIP-like immunoreactivity in each VIP-like immunoreactive perikaryon was seen.

In the reserpine-treated rat, serotoninimmunoreactive terminals were almost completely absent throughout the SCN (Fig. 4c). The depletion of serotonin-immunoreactivity in terminals was more pronounced than in 5,6-DHT-treated rats. Reserpine caused a marked decrease in the VIP-like immunoreactivity in each perikaryon in the ventral portion, and a decrease in the number of VIP-like immunoreactive fibers and terminals in the dorsal portion of SCN (Fig. 5c). However, in the entire $\mathrm{SCN}$ of reserpine-treated rats, a larger number of neuronal perikarya still retained weak VIP-like immunoreactivity than
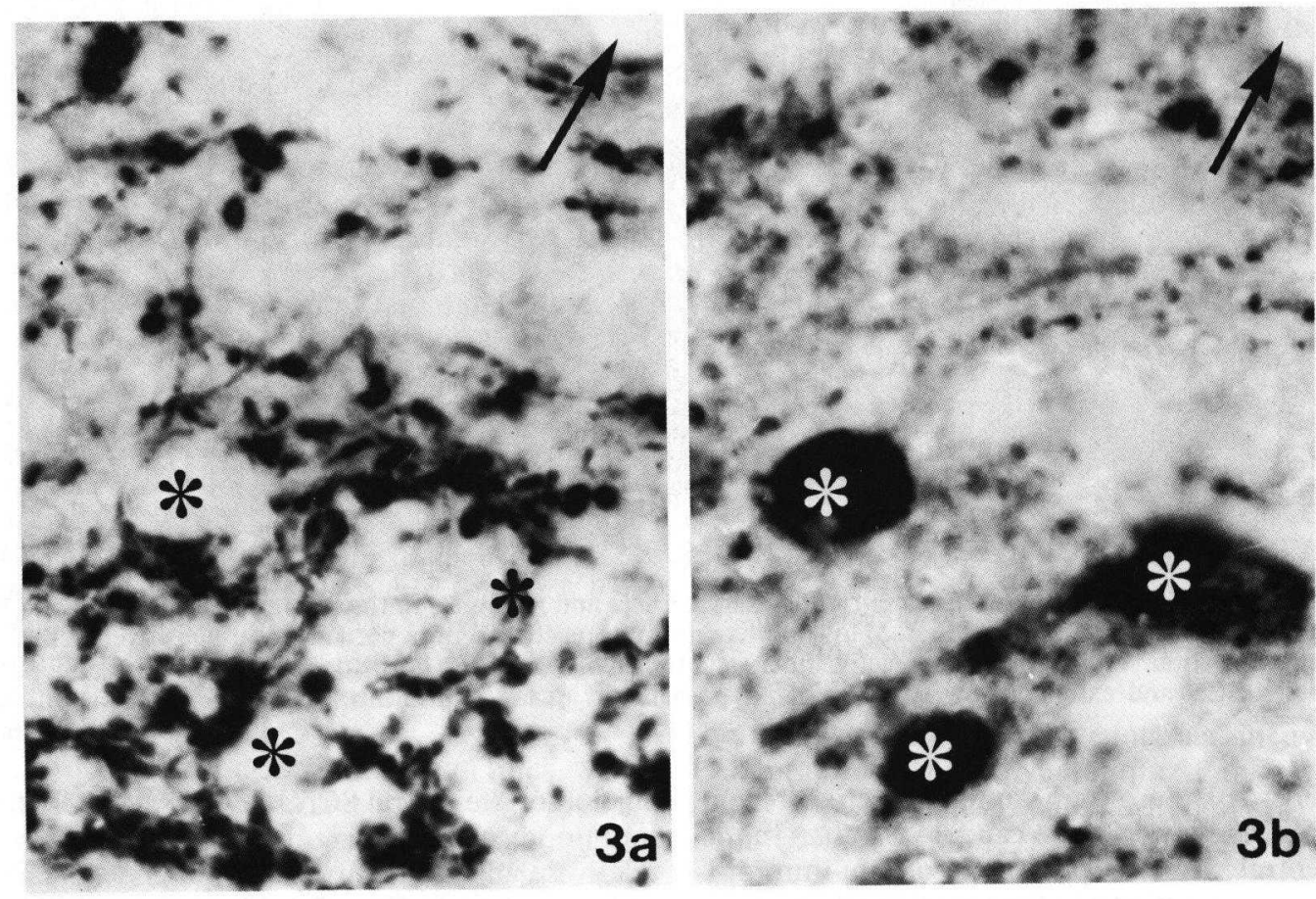

Fig. 3 Higher magnification picture of serotonin-immunoreactive terminals (a) and VIP-like immunoreactive perikarya (b) in serial thin sections ( $4 \mu \mathrm{m}$ thick) from the untreated rat. VIP-like immunoreactive perikarya were surrounded by serotonin-immunoreactive terminals. The site surrounded by serotoninimmunoreactive terminals (a) and the corresponding perikarya showing VIP-like immunoreactivity (b) are indicated by asterisks. Arrows, blood vessels. $\times 1,300$ 

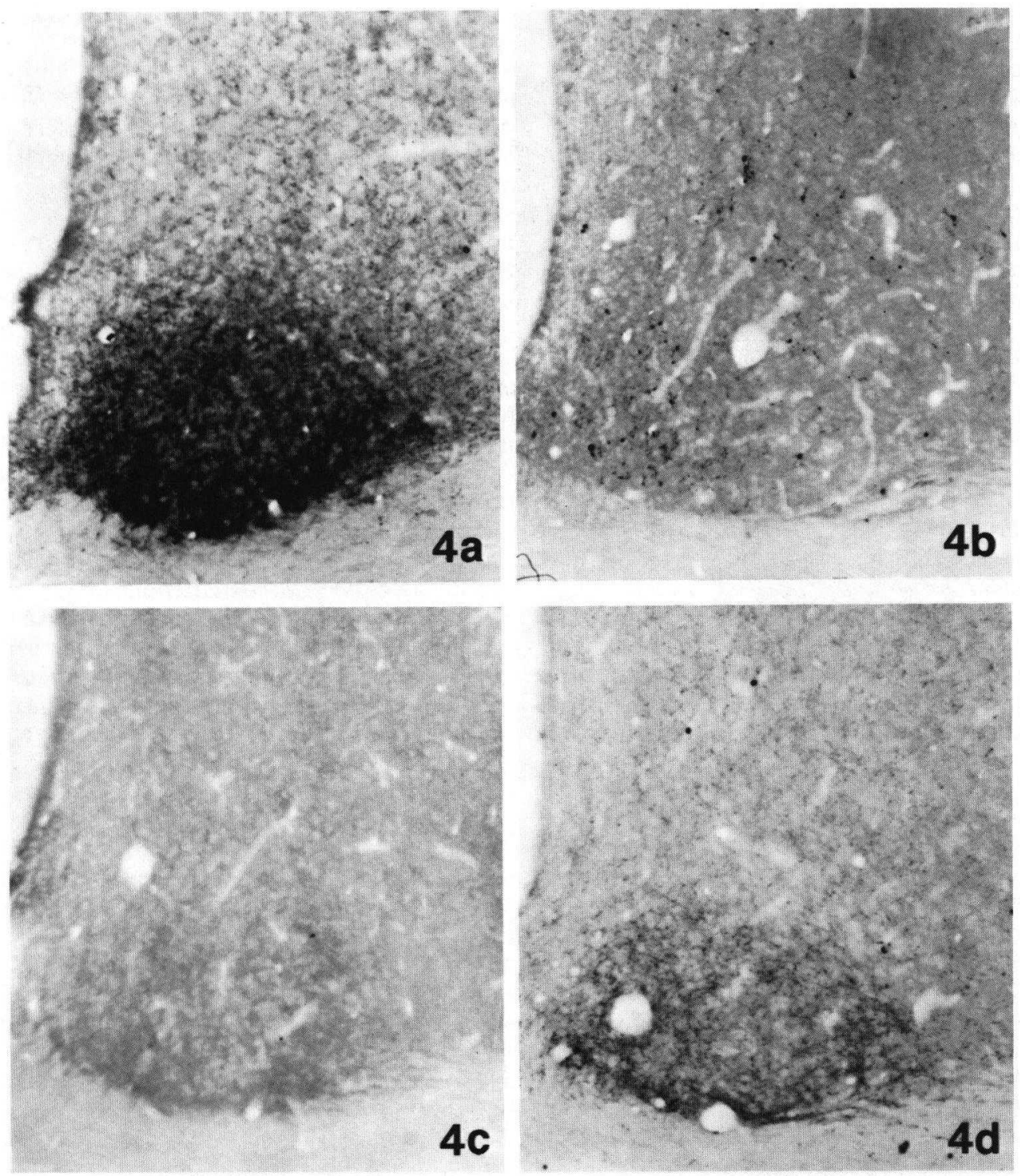

Fig. 4 Alterations in serotonin-immunoreactive terminals in SCN. a: Abundant varicosities in the untreated rat. b: The 5,6-DHT treatment markedly decreased the number of serotonin-immunoreactive terminals. c: Practically no serotonin-immunoreactive terminals were detected after the reserpine treatment. d: The methysergide treatment caused a slight decrease in the number of serotoninimmunoreactive terminals. $\times 125$

in 5,6-DHT-treated rats.

In the methysergide-treated rats, fewer serotonin-immunoreactive terminals were observed throughout the SCN (Fig. 4d). However, the decrease in the number of serotonin-immunoreactive terminals caused by this agent was less than under two other experimental conditions. VIP-like immunoreac- tivity in each immunoreactive perikaryon was reduced compared with the control (Fig. $5 \mathrm{~d})$, but the depletion was also less pronounced than under two other conditions. In the dorsal portion of SCN, no marked differences in VIP-like immunoreactive fibers and terminals were detected between the methysergide-treated rat and the control. 

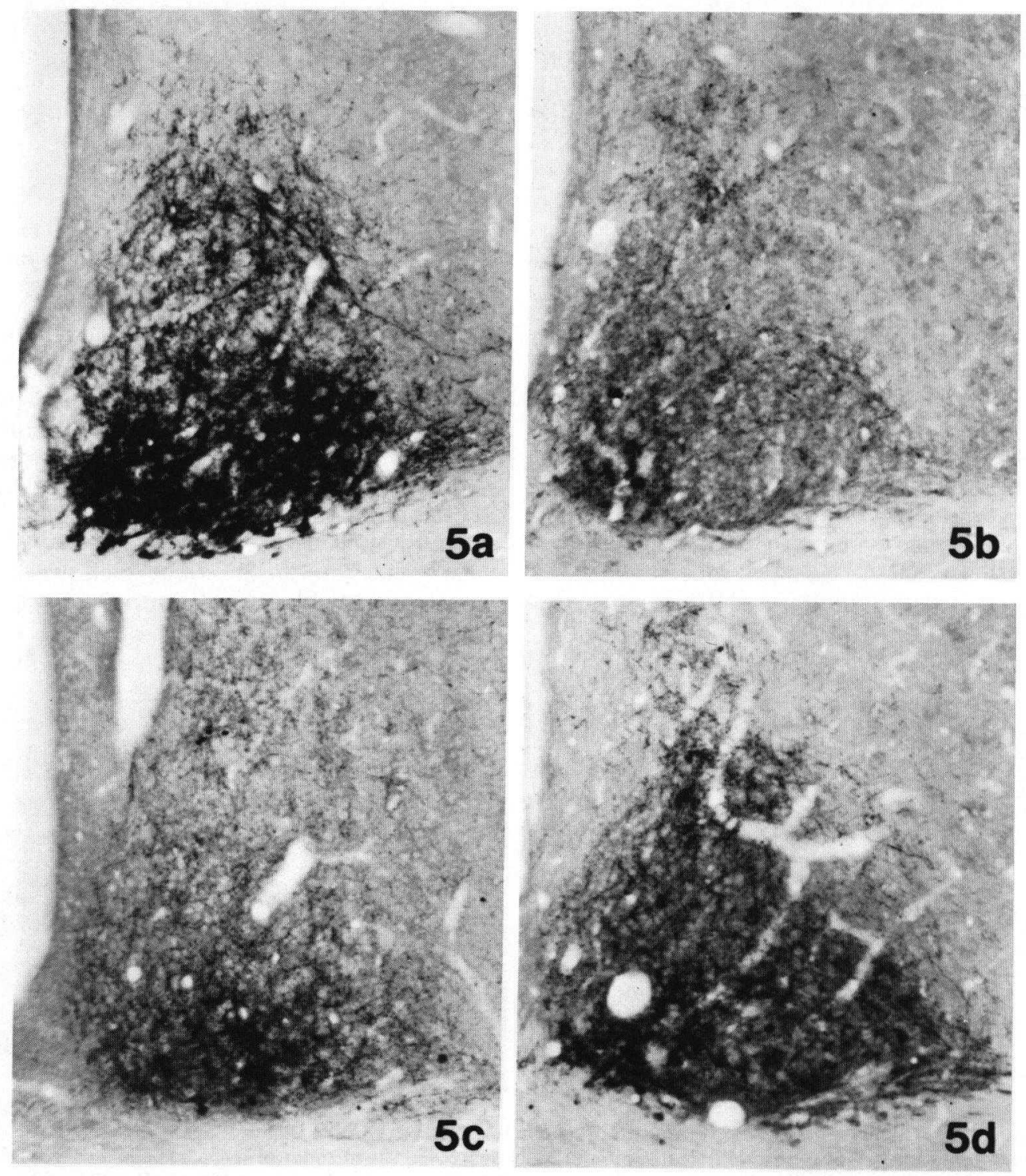

Fig. 5 Changes in VIP-like immunoreactivity in SCN. a: The untreated rat; pronounced VIP-like immunoreactivity is seen in the neuron perikarya in the ventral portion, and in fibers and terminals in the dorsal portion. b: The 5,6-DHT treatment markedly decreased VIP-like immunoreactivity in the neuron perikarya in the ventral portion, and VIP-like immunoreactive varicosities in the dorsal portion. c: Reserpine decreased VIP-like immunoreactivity in SCN, but to a lesser extent than 5,6DHT. d: Methysergide caused a moderate depletion of VIP-like immunoreactivity in the neuron perikarya in the ventral portion. No appreciable difference was seen between the control in VIP-like immunoreactive fibers and terminals in the dorsal portion. $\times 125$ 


\section{DISCUSSION}

In the control rat, serotonin-immunoreactive terminals were mainly located in the ventral portion of SCN throughout the rostral to caudal portions, and serotonin-immunoreactive varicosities were decreased in number toward the dorsal portion. VIP-like immunoreactive perikarya were located in the ventral portion of SCN from rostral to caudal parts, and this pattern was similar to that of the serotonin-immunoreactive terminals. Autoradiography and immunocytochemistry at the electron microscopic level demonstrated synaptic contacts between serotonergic terminals and VIP-like immunoreactive perikarya (15). In agreement with this study, the present observations have shown a similar distribution pattern of serotonin- and VIP-like immunoreactivity in SCN. In addition, careful comparison of alternately immunostained sections strongly supports that serotonin-immunoreactive varicosities are located around VIP-containing somata. It thus appears reasonable to assume that VIP-like immunoreactive perikarya recieve inputs from serotonin neurons.

The treatment with 5,6-DHT markedly decreased the number of serotonin-immunoreactive terminals in SCN by selective degeneration of the serotonin pathway $(4,6,25)$. After the reserpine treatment, almost all the serotonin-immunoreactive terminals also disappeared in SCN by depletion of serotonin in presynaptic terminals. Decrease in the number of serotonin-immunoreactive terminals was moderate in the methysergide-treated rat, presumably because this agent, a specific antagonist against serotonin $(1,2,11)$, accelerates the turnover of serotonin and decreases serotonin in terminals. Both reserpine and methysergide exert an influence not only on the serotonergic system but also on the catecholaminergic system. However, these drugs are considered to affect mainly the serotonergic system in case of SCN since most of the monoamine-containing terminals in this nucleus of rats belong to serotonin neurons. $(8,26,33,34)$.

All the treatment used in this study markedly decreased VIP-like immunoreactivity in the neuron perikarya in SCN compared with the control. However, effects of the 5,6-DHT treatment were stronger than under the two other experimental conditions. In the dorsal portion of SCN, a marked decrease in the number of VIP-like immunoreactive varicos- ities was observed after the 5,6-DHT treatment and a moderate decrease after the reserpine treatment. The methysergide treatment caused only a slight decrease in the number of VIP-like immunoreactive varicosities in the dorsal portion of $\mathrm{SCN}$, and the decrease in VIP-like immunoreactivity was restricted to the neuron perikarya in the ventral portion of SCN. Blockade of serotonergic inputs by methysergide was considered to be less complete compared with the two other experimental conditions.

$\mathrm{SCN}$ in mammals plays an important role as a pacemaker of circadian rhythm, as evidenced by impairment of hormonal activity (21), pineal $N$-acetyltransferase activity (23), drinking behavior and locomotor activity (29) caused by lesions on SCN. SCN is divided into two portions (20): the ventral por tion where neuronal inputs from a number of brain regions arrive $(10,22)$ and are integrated with intrinsic neuronal circuit in SCN; and the dorsal portion whose outputs affect the circadian rhythm. Some VIP-like immunoreactive neurons have been suggested to be intrinsic neurons by immunoelectron microscopy (24).

The present results strongly suggest that serotonergic inputs facilitate synthesis and/or transport of VIP in SCN. It is also suggested that the VIP-like immunoreactive neurons in the ventral portion of SCN are mainly intrinsic neurons that act on other neurons in the dorsal portion such as arginine-vasopressincontaining neurons which may project outside SCN (12). It is also possible that VIP-containing neurons directly project outside, e.g. to the paraventricular nucleus of the hypothalamus, since immunocytochemical investigation suggest such features. In conclusion, the present study indicates that VIP-containing neurons participate in the regulation of the circadian rhythm under the strong influence of serotonergic innervation.

I thank Professor Teruo Nakajima and Emeritus Professor Nobukatsu Kato (Department of Psychiatry), and Professor Yasuhiko Ibata (Department of Anatomy) of this University for their guidance and criticism during this study. Thanks are also due to Professor Noboru Yanaihara, Laboratory of Bioorganic Chemistry, Shizuoka College of Pharmacy, for his generous gift of antiserum, and to Dr Kenji Fukui, Department of Psychiatry of this University for his helpful advice. 
Received for publication 2 October 1985; and in revised form 22 February 1986

\section{REFERENCES}

1. Bennett J. L. and Aghajanian G. K. (1974) DLSD binding to brain homogenates: Possible relationship to serotonin receptors. Life Sci. 15, 1935-1944

2. Bennett J. P. and Snyder S. H. (1975) Stereospecific binding of $\mathrm{D}$-lysergic acid diethylamide (LSD) to brain membranes: Relationship to serotonin receptors. Brain Res. 94, 523-544

3. Besson J., Rotsztejn W., Poussin B., Lhiaubet A. M. and Rosselin G. (1982) Release of vasoactive intestinal peptide from rat brain slices by various depolarizing agents. Neurosci. Lett. 28, 281-285

4. Björklund A., Nobin A. and Stenevi U. (1973) Effects of 5,6-dihydroxytryptamine on nerve terminal serotonin and serotonin uptake in the rat brain. Brain Res. 53, 117-127

5. Consolazione A., Milstein C., Wright B. and Cuello A. C. (1981) Immunocytochemical detection of serotonin with monoclonal antibodies. J. Histochem. Cytochem. 29, 1425-1430

6. Daly J., FuXe K. and Jonsson G. (1973) Effects of intracerebral injections of 5,6-dihydroxytryptamine on central monoamine neurons: Evidence for selective degeneration of central 5hydroxytryptamine neurons. Brain Res. 49, 476-482

7. Emson P. C., Fahrenkrug J., Schaffalitzky De MucKadell O. B., Jessell T. M. and Iversen L. L. (1978) Vasoactive intestinal polypeptide (VIP): Vesicular localization and potassium evoked release from rat hypothalamus. Brain Res. 143, 174-178

8. FuXe K. (1965) Evidence for the existence of monoamine neurons in the central nervous system. IV. The distribution of monoamine terminals in the central nervous system. Acta Physiol. Scand. 64, Suppl. 247, 38-85

9. Giachetti A., Said S. I., Reynolds R. C. and Koniges F. C. (1977) Vasoactive intestinal polypeptide in brain; Localization in and release from isolated nerve terminals. Proc. Natl. Acad. Sci. USA 74, 3424-3428

10. GüldneR F. H. (1978) Synapses of optic nerve afferents in the rat suprachiasmatic nucleus. II. Structural variability as revealed by morphometric examination. Cell Tissue Res. 194, 37-54

11. HAšKovec L. and SoučeK K. (1968) Trial of methysergide in mania. Nature 219, 507-508

12. Hoorneman E. M. D. and BuiJs R. M. (1982) Vasopressin fiber pathways in the rat brain following suprachiasmatic nucleus lesioning. Brain Res. 243, 235-241

13. Kawakami F., Fukui K., Okamura H., Morimoto N., Yanaihara N., NakaJima T. and IBATA Y.(1984) Influence of ascending noradrenergic fibers on the neurotensin-like immuno- reactive perikarya and evidence of direct projection of ascending neurotensin-like immunoreactive fibers in the rat central nucleus of the amygdala. Neurosci. Lett. 51, 225-230

14. Kawakami F., Fukui K., Okamura H., NakaJima T., Yanaihara N. and Ibata Y. (1984) Influence of ascending noradrenergic fibers on the neurotensin-like immunoreactive neurons in the rat paraventricular nucleus. Neurosci. Lett. 44, 149-154

15. Kiss J., Léránth Cs. and Halász B. (1984) Serotoninergic endings on VIP-neurons in the suprachiasmatic nucleus and on ACTH-neurons in the arcuate nucleus of the rat hypothalamus. A combination of high resolution autoradiography and electron microscopic immunocytochemistry. Neurosci. Lett. 44, 119-124

16. KöNIG J. F. R. and KLIPPEL R. A. (1963) The Rat Brain: A Sterotaxic Atlas of the Forebrain and Lower Parts of the Brain Stem. Williams and Wilkins, Baltimore, U.S.A.

17. Lorén I., Emson P.C., FAhrenkrug J., BJörKLUND A., Alumets J., HÅKanson R. and SundLER F. (1979) Distribution of vasoactive intestinal polypeptide in the rat and mouse brain. $\mathrm{Neu}$ roscience 4, 1953-1976

18. Marley P. and Emson P. (1982) VIP as a neurotransmitter in the central nervous system. In Vasoactive Intestinal Peptide (ed. SAID S. I.) Raven Press, New York, pp. 341-360

19. Mezey É., Kiss J. Z., Skirboll L. R., GoldSTEIN M. and AXELRoD J. (1984) Increase of corticotropin-releasing factor staining in rat paraventricular nucleus neurons by depletion of hypothalamic adrenaline. Nature 310, 140-141

20. Moore R. Y. (1982) The suprachiasmatic nucleus and the organization of a circadian system. Trends Neurosci. 5, 404-407

21. Moore R. Y. and EichLeR V. B. (1972) Loss of a circadian adrenal corticosterone rhythm following suprachiasmatic lesions in the rat. Brain Res. 42, 201-206

22. Moore R. Y., Gustafson E. L. and Card J. P. (1984) Identical immunoreactivity of afferents to the rat suprachiasmatic nucleus with antisera against avian pancreatic polypeptide, molluscan cardioexcitatory peptide and neuropeptide Y. Cell Tissue Res. 236, 41-46

23. Moore R. Y. and Klein D. C. (1974) Visual pathways and the central neural control of a circadian rhythm in pineal serotonin $N$-acetyltransferase activity. Brain Res. 71, 17-33

24. Овata-Tsuto H. L., Tsuto T., Okamura H., Kubo T., Fukui K., Yanaihara N. and Ibata Y. (1984) The fine structures of the VIP-like immunoreactive neurons in the cat hypothalamus. Brain Res. Bull. 12, 315-321

25. RichaRDS G. (1983) Ultrastructural visualization of biogenic monoamines. In Handbook of Chemical Neuroanatomy Vol 1: Methods in Chemical Neuroanatomy (ed. BJörkLUND A. and HöKfElt T.) Elsevier, Amsterdam, pp. 122-146 
26. Silverman A. J. and Pickard G. E. (1983) The hypothalamus. In Chemical Neuroanatomy (ed. Emson P. C.) Raven Press, New York, pp. 315336

27. Sims K. B., Hoffman D. L., Said S. I. and ZimMERMAN E. A. (1980) Vasoactive intestinal polypeptide (VIP) in mouse and rat brain. An immunocytochemical study. Brain Res. 186, $165-183$

28. Steinbusch H. W. M. (1981) Distribution of serotonin-immunoreactivity in the central nervous system of the rat-cell bodies and terminals. Neuroscience 6, 557-618

29. Stephan F. K. and Zucker I. (1972) Circadian rhythms in drinking behavior and locomotor activity of rats are eliminated by hypothalamic lesions. Proc. Natl. Acad. Sci. USA 69, 1583-1586

30. Stetson M. H. and Watson-Whitmyre $M$. (1976) Nucleus suprachiasmaticus: The biological clock in the hamster? Science 191, 197-199

31. Stopa E. G., King J. C., Lydic R. and Schoene W. C. (1984) Human brain contains vasopressin and vasoactive intestinal polypeptide neuronal subpopulations in the suprachiasmatic region.
Brain Res. 297, 159-163

32. TAylor D. P. and Pert C. B. (1979) Vasoactive intestinal polypeptide; specific binding to rat brain membranes. Proc. Natl. Acad. Sci. USA 76, 660-664

33. Ueda S., Kawata M. and Sano Y. (1983) Identification of serotonin- and vasopressin immunoreactivities in the suprachiasmatic nucleus of four mammalian species. Cell Tissue Res. 234, 237-248

34. UNGERSTEDT U. (1971) Stereotaxic mapping of the monoamine pathways in the rat brain. Acta Physiol. Scand. Suppl. 367, 1-48

35. Vandesande F., DierickX K. and De Mey J. (1975) Identification of the vasopressin-neurophysin producing neurons of the rat suprachiasmatic nuclei. Cell Tissue Res. 156, 377-380

36. Yanaihara C., Sakagami M., Mochizuki T., Sato H., Yanaihara N., Iwanaga T., Fuji S. and Fujita T. (1980) Immunoreactive VIP (vasoactive intestinal polypeptide) in canine intestinal mucosa and muscle. Biomedical Res. 1, 449-455 